\title{
GCU
}

Glasgow Caledonian

University

University for the Common Good

\section{Banning glassware from nightclubs in Glasgow (Scotland): observed impacts, compliance and patron's views}

Forsyth, Alasdair

Published in:

Alcohol and Alcoholism : international journal of the Medical Council on Alcoholism

DOI:

10.1093/alcalc/agm142

Publication date:

2008

Document Version

Author accepted manuscript

Link to publication in ResearchOnline

Citation for published version (Harvard):

Forsyth, A 2008, 'Banning glassware from nightclubs in Glasgow (Scotland): observed impacts, compliance and patron's views', Alcohol and Alcoholism : international journal of the Medical Council on Alcoholism, vol. 43, no. 1, pp. 111-117. https://doi.org/10.1093/alcalc/agm142

\section{General rights}

Copyright and moral rights for the publications made accessible in the public portal are retained by the authors and/or other copyright owners and it is a condition of accessing publications that users recognise and abide by the legal requirements associated with these rights.

Take down policy

If you believe that this document breaches copyright please view our takedown policy at https://edshare.gcu.ac.uk/id/eprint/5179 for details of how to contact us. 


\section{Banning glassware from nightclubs in Glasgow (Scotland): Observed impacts, compliance and patron's views}

Dr Alasdair J M Forsyth PhD,

Senior Research Fellow

Scottish Centre for Crime and Criminal Justice Research

Glasgow Centre for the Study of Violence

Glasgow Caledonian University

Cowcaddens Road,

Glasgow G4 0BA

Correspondence: Dr Alasdair J M Forsyth, Department of Psychology, Glasgow Caledonian University, Cowcaddens Road, Glasgow G4 0BA, UK Tel. 0141-331-8301. Fax: 0141-331-3636. E-mail: Alasdair.Forsyth@gcal.ac.uk.

\section{Statement of competing interest}

This paper is based on research funded by the Alcohol Education Research Council (AERC).

\section{Acknowledgements}

The author would like to thank Andy Boyd, Jemma Lennox, Katie O'Neil and Tom Woods who acted as the field observers in this research, as well as Professor Kathryn Graham Kathryn Graham of the Centre for Addiction and Mental Health, University of Western Ontario, London, Canada for her kind permission to use her research instruments, and two anonymous reviewers of this manuscript. 


\begin{abstract}
Aims: To examine the impact of a glassware ban policy on disorder-related harm within licensed premises (nightclubs) and how this was action viewed by their patrons. Methods: Field observations were conducted in a sample of 8 nightclubs following the introduction of this policy across all such venues within a city centre. These observations involved both quantitative and qualitative data collection observing violence in a naturalistic setting and were supplemented by taped in-depth interviews with nightclub patrons. Results: Exemptions to the ban had enabled some (3/8) premises to continue to serve alcoholic drinks in glass vessels and injurious violence resulting from these practices was observed. Disorder in all-plastic venues was observed to incur less injury risk. Patrons also reported feeling safer in these nightclubs than elsewhere. Conclusions: This research demonstrated the potential of such policy to reduce the severity of alcoholrelated violence in the night-time economy. It is recommended that future bans of this nature be tailored towards the elimination of all types of glassware from such premises.
\end{abstract}

Keywords: glassware, licensed premises, violence prevention

Word counts: $\quad$ Abstract -167 (including headings)

Text - 4,141 (5,682 including data quotes) 


\section{Introduction}

On February $2^{\text {nd }} 2006$ a Glasgow City Council bye-law was introduced banning glassware from all venues holding an Entertainment Licence within the city's centre. Premises eligible to apply for such a license are those defined under the Civic Government (Scotland) Act 1982 as “a place where on payment of money or money's worth, members of the public are admitted or may use any facilities for the purpose of entertainment or recreation", where licensed for the sale of alcohol such premises are permitted to remain open outwith the permitted hours of the Licensing (Scotland) Act 1976 (Scottish Parliament, 2005). In practice this meant the policy only affected any city centre premises serving alcohol after midnight (i.e. nightclubs).

This move was implemented as part of a range of measures aimed at reducing violence in the city's night-time economy, others included restrictions on alcohol promotions (e.g. a 'happy hours' ban), improved transport services (e.g. establishing taxi marshalled 'nitezones'), the encouragement of safer premises schemes (e.g. the Best Bar None awards) and social marketing designed to encourage sensible drinking (GCCAAG, 2006). The glassware policy aimed at the phased elimination of glass, other than special 'safety' glass (with a target of achieving $80 \%$ plastic or aluminium during 2006), the sole exception to this being made with champagne / wine glasses, for which individual premises could apply for an exemption (see, http://www.sllp.co.uk/Glasgow\%20Glass\%20Revised.pdf accessed June 2007, City of Glasgow Licensing Board, 2006, for full details of this policy).

The removal of glassware from licensed premises has been proposed as an important step in enhancing community safety by reducing the severity of both alcohol-related assaults 
and nightclub accidents (e.g. Luke et al, 2004; Shepherd, 1994). Although there is some evidence that certain forms of glass vessel may be less injurious that others (e.g. that assaults with bottles cause less serious injuries than those inflicted with drinking glasses, Coomaraswamy \& Shepherd, 2003) there is no such thing as safe glass. Even special types of glass, often termed 'safety' glass, such as tempered or toughened glass (which can be stronger than ordinary annealed glass and tends to smash into small thumbnailsized fragments) have been demonstrated to cause significant injuries to both assault victims and via accidental breakages (Cole et al 1994; Warburton \& Shepherd, 2000). In contrast it has been argued that plastic drinking vessels will not break into objects that can be used as weapons (Jonathon Shepherd cited in Winder \& Wesson, 2006). Plastic drinking vessels can be manufactured in many forms including polypropylene (least expensive, disposable and which, because of their flexible nature, cannot be government stamped), polystyrene (another inexpensive material, often in disposable cup form, although they can be reused), polycarbonate (an oil-based material with good clarity, more expensive but 'unbreakable' and malleable into a full range of glassware designs) and finally polyethylene terephthalate or PET (usually semi-rigid clear bottles, which can easily be recycled).

Prior to this policy's introduction, Glasgow had an unenviable level of 'glassings' (barroom assaults where glass vessels are used as weapons). In 2005, 81 such incidents were reported in the city (MacDonell, 2006). This figure is likely to be an underestimate because many such assaults, including some of the most serious, are not reported to the police (Shepherd, 2000; Musson, 2006). Figures released by Glasgow's licensing board convener revealed that 59 'glassings' were treated by Glasgow hospitals' A\&E departments in the year prior to the ban (37 of which had occurred in entertainment 
licensed premises) compared with only five such incidents in the first six months after the ban (Musson, 2006).

\section{Method}

The research undertaken for this paper had two distinct phases. Firstly, a sample of eight Glasgow city centre nightclubs was observed between February and May 2006 (i.e. with fieldwork beginning straight after the ban came into force). Secondly, in-depth face-toface interviews were conducted by the author with 32 patrons of Glasgow's nightclubs between May and September 2006 (i.e. beginning after observations had ceased).

The observational phase of research involved two teams of two fieldworkers, comprising one female and one male observer in each team, visiting each selected nightclub twice, once on a Friday and once on a Saturday, midnight to 3.00AM (which approximates to 100 hours of observation taking into account 'drinking up time').

The eight nightclubs chosen were selected from Glasgow's 70 nightclubs, in consultation with the local police (Strathclyde Police), to represent the range of call-outs to disorder which they received from such premises in the city centre (i.e. including some premises with high and some with low levels of recorded violent crime). These premises all held an Entertainment License (i.e. they served alcohol till 3.00AM at weekends), charged admission at the door and offered mainstream 'high street', regular dance promotions (i.e. the sample excluded niche venues such as Gay clubs, strip clubs, comedy clubs, ceilidhs or ticketed rave promotions). Each of the observed premises was assigned a suitable pseudonym for the purposes of this paper. Table 1 displays some of the characteristics of each of these eight premises, including the number of crimes of 
disorder reported to the police in each during 2005 (i.e. data used in the sampling process) and the corresponding figures for the first six months of 2006 (i.e. 5 months of which was post glass ban and including the whole observation period), as well as observers' mean estimates of basic patron demographics.

\section{$<$ Table 1>}

Observers made extensive field-notes about what they had witnessed on each occasion that they visited a nightclub. On returning home after each observational session, they also completed two quantitative research instruments (questionnaires or checklists). These instruments and this methodology have been extensively used in Canada by Professor Kathryn Graham and colleagues (see Graham, 1999 \& 2000). The first of these, 'Form 1', was used to detail the drinking environment within each nightclub. Items were included in 'Form 1' to gauge the impact of the glassware ban (including items relating to whether the ban was being complied with and if so what type of materials, e.g. plastic or 'special glass' were now in use). Observers were allowed to purchase one alcoholic and one non-alcoholic beverage per session and so they also had the opportunity to examine drinking vessels at first hand. The other instrument, 'Form 2', was used to record any incidents of violence witnessed, regardless of whether or not glass was involved. Observers were not informed of why the eight nightclubs in the sample had been chosen, though given the publicity surrounding the glass ban they would have been aware of the salience of this issue.

Patron interviewees were recruited firstly via the observers handing out project recruitment cards to clubbers $(n=8)$. This policy was abandoned after one weekend 
when a newspaper journalist responded. Next clubbers were recruited via chain-referral from students ( $n=17$, not the students themselves) attending the author's institution. (Note - According to The Times Good University Guide, 2007, Glasgow Caledonian "is among the top UK universities for attracting students from areas without a tradition of higher education, and more than a third of its undergraduates come from working-class homes"). Finally direct approaches were made by the author on the streets of Glasgow city centre, targeting demographic types (e.g. teenagers) apparent in observations but not already recruited for interview $(n=7)$. Only one person approached in this fashion refused to be interviewed (stating he was "too young to get in" to nightclubs). Interviews lasted approximately 30 minutes, were semi-structured, taped and, with the exception of the first interview, and those conducted on the street, were held at the university. Respondents were provided with an information sheet which stressed the confidential nature of the research, and a consent form. All participants were paid a small sum for their participation (a total of $£ 20.00$ per interview). The interview topic guide explored interviewees' experience of Glasgow's night-time economy and included the prompt "Views on glassware ban". Fuller details of this research, its rationale, methods and findings can be found elsewhere (Forsyth, 2006).

\section{Results}

\section{Observations in nightclubs (impact on disorder severity)}

During observations, observers estimated the percentage of patrons who appeared to be consuming each of ten categories of alcoholic beverage and which type of drinking vessel each of the eight nightclubs sold each of these beverages in. In practice, three beverages, vodka (overall mean estimated number of patrons observed consuming $39.9 \%)$, lager (40.4\%) and alcopops (32.3\%), were clearly more popular in this drinking 
environment than others (other spirits, $9.1 \%$; other beer, $0.2 \%$; cider, $0.1 \%$; wine, $1.0 \%$; champagne, $0.2 \%$; cocktails, $1.4 \%$; shots, $1.8 \%$ ). (Note that these percentages do not sum to $100 \%$ as patrons often consumed more than one type of beverage.)

A number of factors complicated this task. Firstly, some drinks (champagne and wine) were exempt from the glassware ban, however these were very rarely observed. Secondly, nightclub operators were allowed under the terms of the Glasgow bye-law to use drinking vessels made from special 'safety' glassware (i.e. toughened or tempered). In practice, it was therefore impossible for observers to be $100 \%$ accurate when determining what type of glass they were drinking out of never mind what else they were observing. Thirdly some drinks were served in materials other than glass, 'special glass' or glass substitutes (i.e. plastic), such as aluminium cans of beer or ceramic pitchers of cocktails. However, despite these limitations to the identification of 'special' as opposed to 'ordinary' glass, clear patterns in the adoption of plastic or otherwise were observed between individual nightclubs and between beverages.

Table 2 shows the estimated observations of glass or plastic for the three most commonly observed beverages in this research (i.e. vodka, lager and alcopops). This table notes the type of vessel which observers believed that each of these three beverages was typically being sold in, by each of the eight nightclubs in the sample during each visit. Where special 'safety' glass (i.e. toughened or tempered) was thought to have been observed, this is recorded by the columns headed 'SG'. Plastic is recorded in the columns headed ' $\mathrm{P}$ ' and ordinary glass in the columns headed ' $\mathrm{OG}$ ' (these latter figures initially being estimated from any chips or breakages witnessed during observations). 
In practice each vessel for each drink in each nightclub could be observed up to eight times (i.e. during both visits by each of the four observers). So for example, Table 2 indicates that all four observers noted that 'Armageddon' was selling vodka in plastic vessels on both occasions that they visited this venue (column 'P') and therefore none were selling this beverage in glass (neither 'ordinary' annealed glass, 'OG' nor 'special' tempered glass ' $\mathrm{SG}$ '). However as can also been seen from Table 2, it was not possible on some occasions for an individual observer to determine what the vessels that some products were being sold in were made of (i.e. where cells do not sum to eight observations), if some premises did not stock some products or if an observer did not observe the product concerned sufficiently during that visit, nevertheless it is noteworthy that all four observers (on both of their visits) were in agreement about which premises were still using glass.

\section{$<$ Table 2 here $>$}

The most apparent feature of Table 2 was that most (i.e. five of the eight premises) appeared to be plastic only (as far as these commonly consumed beverages are concerned). Interestingly, the three premises which were still serving in glass vessels (of any type) were those which were also observed as having relatively older clienteles (see Table 1). In two of these, 'Tropicana' and 'Sinatra's', more than one-third of patrons were estimated to be aged over 30 years (compared with $15.1 \%$ for the sample as a whole), while the third glass serving nightclub, 'Saturn', had the next highest proportion of over 30s (though this did not differ significantly from the sample mean) and was the only nightclub where under-18s were never observed, with the clientele here being described as, for example, "Patrons older in mid-twenties." (Female Observer, 'Saturn'). Further, all three of these nightclubs appeared to be using ordinary glass for some 
beverages (e.g. branded lager pint tumblers in 'Sinatra's' and small, thick, 'rock glass' vessels for spirits in 'Saturn').

When examining Table 2 by beverage, rather than premises, another interesting pattern appears in that in only one instance did an observer note that alcopops were not being served in plastic. Again this may relate to age, as younger consumers tended to go for this drink, whereas pints were preferred by older patrons (something which patron interviews also bore out). The one occasion where an observer felt that even alcopops were not being sold in plastic took place in 'Tropicana'. Observers' experiences in this nightclub illustrate the complexities involved in the task of identifying the medium in which drinking vessels have been manufactured. Here the practice was to open glass bottles (e.g. of branded beer) and then pour their contents into small 'glasses', giving the impression that the beverage concerned was being transferred from ordinary glass to 'special glass' in order to comply with the bye-law, as is described in the following observer's field-note.

"Think it was toughened glass as they were all pouring lager from bottles into glasses. There was still big glass ashtrays out though." (Female Observer, 'Tropicana' - first data collection sweep)

However, on this observers' final nightclub visit it transpired that this was not the case. A ruse like the one described below implies that the level of ordinary glass shown in Table 2 may in fact be an underestimate.

"When we came in we went to the bar. I ordered a vodka and [Male Observer] got a bottle of Budweiser [lager]. My glass didn't look like toughened glass and the barman poured [Male Observer]'s bottle of Bud into the same type of glass. I asked the barman why he poured the bottle into the glass. He said it was due to Glasgow bye-laws. I asked if the glasses were a special type of glass and he said no. I wanted to be sure so I said "I know you can get special toughened glass, is this not it?". He said no and it was pointless and stupid putting the contents of the 
bottles into glasses and was a pain in the arse for bar staff." (Female Observer, 'Tropicana' - second sweep)

Even when drinking vessels were smashed it was difficult for observers to be certain as to what type of glass was being used, as the following field-note describing a violent incident in 'Sinatra's' illustrates.

"DJ said something over the microphone to the effect "fight in front of the DJ box"... [We] Went round to the back of the DJ box and found S1, S2 and S3 [stewards] tending to P1 [a male patron] who was bleeding badly from his neck / shoulder area... When [Male Observer] and I walked back to O1 [observation point] we saw lots of broken glass on the floor. It might have been toughened glass as it seemed to be broken into little squares but might just been smashed down by people walking on it. I've never seen toughened glass before so I couldn't say for sure.” (Female Observer, 'Sinatra's' - 02.30 AM)

A few minutes after the above incident, a second fight broke out which convinced these observers that ordinary glass was involved (extracts from the field-notes of both of the observers who witnessed this aggressive incident are given below).

"Then two males (P1 and P2) started fighting at table next to us. P1 [tattooed 2830 year-old in white shirt] lunged over at P2 [27-30 year-old in white shirt] and the two began brawling on to the floor in front of us. Both were tumbling about trying to get each other in headlocks and swinging punches. Both were red in the face and their faces were contorted in anger. They were like this for a good couple of minutes with no intervention from stewards despite patrons chanting "fight fight fight". Then P2 threw a glass at P1 which missed P1 and hit the wall showering the people sitting there with glass..." (Female Observer, 'Sinatra's' 03.05 AM)

“...I didn't see any scarrings on P1 [tattooed 28-30 year-old male in white shirt] as he was taken past me and [Female Observer] to the fire exit. However a guy who had been sitting near the incident had blood on his shirt. Don't know how badly P1 was injured or if anyone had been hurt by the shattered glass from the glass hitting the wall.” (Male Observer, 'Sinatra's')

These two aggressive incidents, within minutes of each other in the same nightclub, clearly illustrate the potential for glass to cause injury. In contrast, the following incident (described by the same male observer) which took place at 'Xanadu' (a glass-free nightclub) shows how the use of plastic vessels can clearly minimise injury risk. 
"As I saw it P1 [male in leather jacket] was punching P2 [male with ponytail] really hard. P2 was punching back and about three of his friends were attempting to fight back with punches. P1 even picked up a plastic bottle (by chance it was the new Vodka Ctrl bottle [a plastic only alcopops brand]) and was hitting out with it. After two calls from the DJ that a fight was occurring S1 [male steward] ran behind P2 and his friends..." (Male Observer, 'Xanadu')

In the above incident it seems reasonable to assume that the male in the leather jacket would not have had time in the heat of the moment to decide that the weapon he had picked up was plastic and not glass ('special glass' or otherwise). Were it not for the glassware ban, and the compliance of this nightclub, 'Xanadu's', management with this bye-law, then it is all too easy to see how this incident could have become much more serious. Indeed, in such all-plastic venues the advantages of removing glassware were not restricted to violence severity reduction, but extended across a range of public safety or accident reduction issues which affected both patrons and staff.

"One guy knocked his drink over on the table and just threw the cup across the room. People chucking glow-sticks about and lots of horseplay. There was a sign saying no drinks or smoking on the dancefloor but this was ignored by both patrons and staff, and girls were dancing in their bare feet." (Female Observer, 'Xanadu')

As a result of witnessing such behaviour, observers began to feel safer themselves while working in glass-free environments, regardless of other factors such as number of aggressive incidents witnessed, clientele or staff practices. For example, in the nightclub where the highest levels of disorder was observed, 'Armageddon' (see Table 1), observers felt relatively safe, as these fights were never injurious, in contrast to those described above in 'Sinatra's' where much fewer incidents were witnessed.

"Even though there was more trouble in 'Armageddon', I felt safer there in comparison because; A: it was minor scuffles not glassings, B: you couldn't look around 'Armageddon' without seeing a security staff member monitoring various parts of the club, C: the security staff looked a lot more organised and not fannying about collecting glasses, which ironically was the very thing causing extreme violence in 'Sinatra's'." (Male Observer, 'Sinatra's') 
The later part of the above field-note refers to a practice also apparent in 'Saturn' whereby security staff were observed collecting glasses, presumably to remove the danger that these empties represented, though this practice is also risky.

"Once I saw one security staff member see something that concerned him (it turned out to be nothing) he wanted to consult a nearby bouncer but he had to put down the stack of six glasses that he was carrying on the nearest tables so that he could catch up with his colleague, if something had kicked off this glass collecting would slow response time." (Male Observer, 'Sinatra's')

\section{Interviews with patrons (views on glass-free clubbing)}

These observational findings were confirmed by the Glasgow nightclub patrons interviewed, whose views also endorsed the rationale behind the glassware ban. These interviewees were very positive about the potential of the ban to reduce the severity of violence in nightclubs as is illustrated by the following quotes.

"I don't think it reduces the risk of violence but it reduces the risk of serious injury from violent attack." (Male Patron, \#8)

"Well from working in pubs I did actually see one of my glass collectors getting glassed by a guy."... "...the guy was only a 17 year old boy collecting glasses you know... They were arguing over the Rolling Stones these two guys. And the guy just picked up a glass to hit the other guy and hit the glass collector. Just for the fact that for all the difference, yeah, you've got a plastic cup and you feel like, "why have I got a plastic cup?" That's just, that's saying glass is better. That's somebody somewhere once saying glass is better and you're all believing that. There's no benefit or negativeness if you know what I mean, except you won't get glassed. You know? It's not a weapon any more." (Male Patron, \#7)

The above quote from interviewee \#7 is of particular interest as he was working as a trainee-manager of licensed venue on the outskirts of Glasgow (where the glassware ban had not yet come into effect). He and other interviewees who had worked in the licensed trade industry were amongst the most enthusiastic supporters of this policy. Interestingly, their reasoning came not only from observing the floor (patrons fighting or accidents) but also from the point-of-view of their own convenience as plastic was seen as making their 
job easier and safer (e.g. when washing up) though the financial aspects faced by nightclub operators of introducing plastic were not mentioned.

"It [glass] smashes and it's so much harder to clean up. At least with plastics you just go along with a bin bag and plonk them all in, you know?" (Male Patron, \#7)

"I used to work in [a non-observed Glasgow city centre nightclub] for two months and we used to do glasses but they didn't, they don't, they've not started doing the plastic glasses yet but I think definitely it's a brilliant thing to add these plastic glasses in. Because I mean I've got, I had cuts and everything just for going like ahhh [mimics pain of hand washing injury] smashing glasses. So I like the glass ban." (Male Patron, \#21)

There were however some complaints about the types of plastic being used in some Glasgow’s nightclubs. Soft plastic "cups” such as polypropylene (relatively inexpensive) and polystyrene were much less popular than harder "plastic glasses" made from (relatively more expensive) polycarbonate. This was partly for aesthetic reasons and partly because the former were seen as prone to spillage or splitting, both of which could actually lead to accelerated alcohol consumption by some patrons.

"Well, like last night [in 'Chocolate'] for instance I was holding a vodka and Coke and my mate hit me and glass, the plastic split all the way down the middle. I had to down it and it was a whole new thing so. That can be infuriating but." (Male Patron, \#32)

Additionally, some patrons seemed to view certain plastic containers as 'disposable' and tended to treat them as such creating a litter problem. This view could account for some observers' field-notes, which had described excessive littering, spillage, abandoned drinks, sticky carpets, ice cubes and related hazards on some nightclubs' dance-floors.

"I think it's alright if you've got the sort of thick plastic cups because you tend to like treat them like a glass and you put it down somewhere sensibly you don't just chuck them on the floor." (Male Patron, \#5)

A potential solution to these problems was proposed by some interviewees. This was to increase the use of sealed, spill-proof, plastic bottles which have stoppers through which 
liquid can be drawn (i.e. containers resembling those used for sports drinks). During field observations two of the premises in the sample, 'Xanadu' and 'Rapture', introduced an alcopop called Vodka Ctrl, marketed in such containers, but which was launched as an anti-drink-spiking measure (though the cap could easily be unscrewed). However, some interviewees who had seen this beverage, and the many design advantages it held within the nightclub drinking environment, felt that the concept could be taken further and all drinks could either be served in or poured into such vessels (i.e. in a practice similar to that engaged in at 'Tropicana', but with spill-proof plastic containers rather than glass).

"I kinda used to like them [alcopops] but they're just expensive. I tried. There's one that I noticed that was out that I got that's got one of those caps that..." [Vodka Ctrl?] “...yeah, that you're not allowed, that you can't put anything in it [i.e. spike it], but it tastes disgusting so that kinda, I think it would be quite good if they actually gave you your drink in a bottle like that? They should do that instead of those horrible expensive alcopops, they could just give you a bottle!" (Female Patron, \#11)

When pressed about why they preferred glass, interviewees were often stuck for an answer, however the main themes appeared to be its' childish, downmarket or cheap image, temperature (i.e. cold drinks were believed to warm up quicker in plastic vessels, presumably because these felt less cold in the hand - in fact this indicates that plastics, with a thermal conductivity of around 0.03 to $0.05 \mathrm{~W} / \mathrm{mK}$, can be a better insulator than glass, at $1.05 \mathrm{~W} / \mathrm{mK}$, and as such plastics are even used in the manufacture of special thermally 'insulated glass', The Engineering Toolbox, 2007), taste (i.e. the beverage did not taste the same) and it giving out a negative image of city's nightclubs (though this view was only expressed by a Canadian interviewee).

"In know when you're drinking it's always like there's the cheap comment about, the clubs are so cheap they don't buy glass, but I guess it's a good safety thing. Em, kind of think as a foreigner you sometimes think "oh well what kind of city am I in?" I mean the thought has crossed my mind, I don't know how serious it was, but it's just like why is it plastic and not glass does it have that much potential for [violence?]." (Male Patron, \#2 - Canadian exchange student) 
Interestingly, older patrons tended to be more pro-glass or anti-plastic than younger interviewees. In contrast, some younger patrons were either unaware of the glassware ban before they were interviewed or failed to see why this issue should be controversial. These views are illustrated from the following two statements, the first made by the oldest male patron interviewed, the second by an interviewee whose $18^{\text {th }}$ birthday was during the previous week (i.e. she was only 'over-age' post-ban).

[Why do you prefer glass?] "I don't know! Subjective. Well, it's more special isn't it? Something that's like you're out for a picnic with your daft plastic cups or whatever but in saying that I'd rather drink out of that knowing nobody's going to get a glass in their face." (Male Patron, \#24 - 47 years)

"I think it's a good thing if it stops like people getting obviously, getting angry and glassing people and stuff. But it doesnae really bother me and my friends." ... "I don't get it [why people object to plastic]. It doesnae bother me myself. Just as long as it's got a drink in there, ha, ha, ha." (Female Patron, \#22 - 18 years)

Although all interviewees were positive about the glassware ban being implemented in nightclubs (if in some cases reluctantly so) and could see why it was necessary, their views were more divided about whether it should be extended to pubs and in particular to restaurants. This was largely for reasons relating to movement (in nightclubs) and the view that in other types of licensed premises glassware was an integral part of the service or entertainment that attracted patrons to drink in such venues in the first place.

"Well people pay for like, the service and whatever, whereas in a club you're not really paying for the service as such, so in a restaurant I think it would be a bit stupid to see like all these posh people with their wine in little paper cups." (Female Patron, \#6)

On the other hand, interviewees were in favour of the ban being extended to nightclubs outside Glasgow. The views of patrons who lived or studied outside the city (centre) were particularly illuminating in this regard and they were able to recount stories of glass-related incidents they had witnessed (including those involving serious violence) 
while clubbing away from Glasgow. These contradict the view expressed by the Canadian interviewee \#2, above, and imply that Scottish clubbers see Glasgow as a safer city because of the ban.

"I was recently in a club in Dundee actually, and like there was glass bottles all over the floor and smashing everywhere and I couldn't understand it. I was like why is there glass everywhere people. Do they not have plastic cups and everyone's like, what are you talking about, but yeah, there was glass everywhere and it was horrible because I felt I couldn't dance because I was gonna stand on it and cut myself and everyone else around me was gonna do it as well. They weren't, they weren't noticing it either." (Female Patron, \#6)

The final comment by interviewee \#6 above is of particular interest as it indicates just how rapidly Glasgow's clubbers had become used to the glassware ban.

\section{Discussion}

By observing barroom violence in its naturalistic setting and gaining the views of patrons, this paper has examined some important aspects of the impact of banning glassware from a city centre's nightclubs. However, premises were still allowed to use special 'safety' (toughened or tempered) glass and there was also an exception whereby champagne / wine could still be sold in ordinary glass. Such exemptions are unfortunate, as it was apparent from this research that these allow opportunities for potentially harmful glassware to remain in circulation. Therefore any future polices designed to remove dangerous glassware would benefit from a rigorous monitoring system to ensure compliance by operators.

Another concern was that special 'safety' glassware can also be dangerous, especially in the absence of a manufacturing standard to regulate the standard of tempered glassware (Warburton \& Shepherd, 2000), and that a 100\% plastic policy would have been more effective. This too was borne out during observational research, as 'glassings' were 
witnessed and observers were unable to determine whether or not toughened glass had been used in these assaults. The use of a 'kite mark' in the manufacture of 'safety' glass would have assisted in this task and lessened the likelihood of non-compliance with ban (operators who may attempt to pass off 'ordinary' annealed glass as toughened glass).

Despite these concerns, from the findings of this research there can be no doubt that this policy could be successfully extended to nightclubs elsewhere, which interestingly patrons now viewed as being more dangerous than those in Glasgow for this reason alone. Although interviewees did not like certain types of plastic vessel and some were less positive about extending the glassware ban to pubs, and in particular to restaurants, like the contemporary Scotland wide ban on smoking in public places, on this evidence, patrons will be quick to accept the removal of glassware from nightclubs elsewhere.

Commenting on a research report funded by the glass industry, David Workman, director general of British Glass, stated "After recent attempts to ban glasses and bottles from pubs in Glasgow we felt it was important to demonstrate that such a ban would not have an effect in reducing alcohol-related violence" (British Glass, 2006, http://www.britglass.org.uk/NewsEvents/BGNewsCurrent/NewReportRevealsComplexR o.html, accessed 2007). This is misleading, as it is doubtful whether the medium in which drinking vessels are manufactured (e.g. glass or plastic) can make any difference to the frequency of alcohol related violence within licensed premises. What is not in doubt from this observational study of nightclubs is that when violence does occur within licensed premises, and it does regularly, the severity of injuries caused by drinking vessels can be greatly reduced by a $100 \%$ glass-free environment. 
The author's of glass industry's report Winder and Wesson (2006, page 7) describe a theme where "aggressive customers would probably use other objects in a conflict, if they did not have a glass in their hand at that time" and go on to speculate that "that if plastic vessels were only used, they would use another object (e.g. ashtray)". This research, did also illustrate the potential of glass ashtrays to fulfil this role, however these were withdrawn halfway through observations with the introduction of the Scottish smoking ban on the $26^{\text {th }}$ March 2006. In fact the objects which were observed being used in the absence of glass were plastic. Moreover, the existence of other potentially (usually less) harmful objects in the barroom environment (e.g. barstools or pool cues) should not be allowed to detract from the benefits of removing glassware and arguments that aggressors will simply use whatever potential weapons are available favour the replacement of glass with plastic. This mirrors debates about the availability about guns (access to which can be restricted), as opposed to knives or cricket bats (more difficult to restrict) between the USA and UK (e.g. see Squires, 2000; Eades, 2006).

One negative consequence of the glass-free policy, reported by both observers and interviewees, was that plastic drinking vessels tended to be discarded carelessly. This had implications for littering and floor slipperiness. This is a management issue which needs to be addressed, as tolerance of such behaviour and environmental discomfort have been shown to be predictors of violent disorder (e.g. Graham et al 2000; Homel et al, 2004). Nevertheless, in contrast to a similar study conducted in Glasgow's city centre pubs in the previous year, no one in this research reported any nightclub floors as having " $a$ carpet of glass" (Forsyth et al, 2005). 
It was of interest that the two premises with the most disorderly incidents (from observations or police data, see Table 1) were plastic only. It has been argued that removing glassware may create "a self-fulfilling prophecy" (Winder \& Wesson, 2006, page 45) increasing the likelihood of violence, as some patrons may see this as a signal that they cannot be trusted, or that disorder is tolerated and that choosing to fight here would prove less injurious than elsewhere. However, in the present case (ordinary) glass was banned from all nightclubs in the city centre and therefore the notion of plastic vessels stigmatising individual premises with a violent reputation (whether deserved or not) should not apply. These are issues which should be explored by future research taking place in city centres were only some premises had switched to plastic.

The current research was limited by only observing the situation following the introduction of the policy aimed at removing potentially dangerous glassware (i.e. the extent to which plastic was being used pre-ban is unknown) and also because it was not possible for field observers to remove vessels (legally) in order to conduct any analyses capable of assessing the full characteristics of their manufacture. Future research could address these issues by incorporating a before-and-after design, together with a capacity to conduct laboratory tests on all types drinking vessels circulating in affected premises.

\section{Conclusion}

It has often been said that if alcohol was invented today it would almost certainly be made illegal, most likely as a Class A, Schedule 1 Controlled Drug. Something similar might also be said of glass drinking vessels. If these were invented today they would almost certainly not pass health and safety legislation. In short, as is already accepted with motor vehicles and firearms, alcohol and glass should not mix and on the evidence 
of this research, the replacement of glass with plastic drinking vessels in licensed premises, in particular entertainment / dance venues, is likely to bring substantial public safety rewards. 


\section{References}

British Glass (accessed 2007) New report reveals complex routes of pub violence. http://www.britglass.org.uk/NewsEvents/BGNewsCurrent/NewReportRevealsComplexR $\underline{\text { o.html }}$

City of Glasgow Licensing Board (2006) Amended Policy relative to the use of toughened glass and / or plastic in public house and entertainment licensed premises. http://www.sllp.co.uk/Glasgow\%20Glass\%20Revised.pdf

Cole, J., Plant, M., Miller, P., Plant, M. \& Nichol, P. (1994) Preventing injuries from bar glasses. British Medical Journal, 308, 1237 - 1238.

Coomaraswamy, K. S. \& Shepherd, J. P. (2003) Predictors and severity of injury in assaults with barglasses and bottles. Injury Prevention, 9, $81-84$.

Eades, C. (2006) 'Knife Crime' ineffective reactions to a distracting problem?: A review of evidence and policy. London: King's College, the Centre for Crime and Justice Studies.

Forsyth A. J. M., Cloonan, M. \& Barr, J. (2005) Factors Associated with Alcohol-related Problems within Licensed Premises. Glasgow: Greater Glasgow NHS Board.

Forsyth, A. J. M. (2006) Assessing the relationships between late night drinks marketing and alcohol-related disorder in public space. London, Alcohol Education Research Council.

Graham, K. (1999) Safer Bars: Assessing and Reducing Risks of Violence. Toronto: Centre for Addiction and Mental Health.

Graham, K. (2000) Safer Bars: Training Manual for Observers on the Safer Bars Study. Toronto: Centre for Addiction and Mental Health.

Graham, K., West, P. \& Wells, S. (2000) Evaluating theories of alcohol-related aggression in bars. Addiction, 95: 6, 847 - 864.

GCCAAG (2006) Play Safe in Glasgow: Annual Report 2005 - 2006. Glasgow: Glasgow City Centre Alcohol Action Group.

Homel, R., Carvolth, R., Hauritz, M., Mcllwain, G. \& Teague, R. (2004) Making licensed venues safer for patrons: What environmental factors should be the focus of interventions? Drug and Alcohol Review, 23, 19 - 29.

Luke, L. C., Dewar, C., Bailey, M., McGreevy, D., Morris, H. \& Burdett-Smith, P. (2002) A little nightclub medicine: the healthcare implications of clubbing. Emergency Medicine Journal, 19, 542 - 545.

McDonell, H. (2006) Legal challenge to pub glass ban. The Scotsman, June $2^{\text {nd }}$.

Musson, C. (2006) A way to curb violence... or a waste of time. (Glasgow) Evening Times, December $29^{\text {th }}$. 
Scottish Parliament (2005b) Licensing (Scotland) Act 2005

http://www.scottish.parliament.uk/business/bills/pdfs/b37s2.pdf.

Shepherd, J. P. (1994) Preventing injuries from bar glasses. British Medical Journal, $308,932-933$.

Shepherd, J. P. (2000) Using injury data for violence prevention. British Medical Journal, 321, 1481 - 1482.

Squires, P. (2000) Gun Culture or Gun Control?: Firearms violence and Society. London: Routledge.

The Engineering Tool Box (accessed August 2007) Thermal Conductivity of some common materials.

http://www.engineeringtoolbox.com/thermal-conductivity-d_429.html

The Times (2007) Good University Guide, August $15^{\text {th }}$.

http://www.timesonline.co.uk/tol/life_and_style/education/good_university_guide/article 2166467.ece

Warburton, A. L. \& Shepherd, J. P. (2000) Effectiveness of Toughened Glassware in Terms of Reducing Injury in Bars: a randomised controlled trial. Injury Prevention, 6, 36 -40 .

Winder, B. \& Wesson, C. (2006) Last Orders for Alcohol Related Violence: Exploring salient factors in $U K$ pubs and other late night venues. Report to British Glass. Nottingham: Nottingham Trent University. 
Table 1: Nightclubs characteristics, recorded and observed violence

\begin{tabular}{|l|c|c|c|c|c|c|}
\hline Venue & $\begin{array}{c}\text { Police } \\
\text { Data 2005 }\end{array}$ & $\begin{array}{l}\text { Police Data 1 } \\
\text { 6 months 2006 }\end{array}$ & $\begin{array}{l}\text { Est. } \boldsymbol{n} \text { of } \\
\text { patrons }\end{array}$ & $\begin{array}{l}\text { Est. \% } \\
\text { female }\end{array}$ & $\begin{array}{l}\text { Est. \% } \\
\text { aged 30++ }\end{array}$ & $\begin{array}{l}\text { Incidents } \\
\text { Observed }\end{array}$ \\
\hline Armageddon & 152 & 67 & 246 & 50.6 & 4.4 & 11 \\
\hline Xanadu & 195 & 115 & 241 & 58.5 & 5.0 & 8 \\
\hline Idols & 81 & 50 & 258 & 60.6 & 7.5 & 4 \\
\hline Rapture & 112 & 35 & 251 & 52.5 & 4.4 & 0 \\
\hline Chocolate & 94 & 23 & 197 & 57.6 & 11.9 & 2 \\
\hline Saturn & 6 & 18 & 154 & 45.0 & 16.3 & 0 \\
\hline Sinatra's & 76 & 65 & 248 & 58.8 & 35.6 & 5 \\
\hline Tropicana & 107 & 71 & 252 & 60.6 & 34.8 & 4 \\
\hline
\end{tabular}


Table 2: Observed vessels used post-glassware ban

\begin{tabular}{|l|r|c|c|r|c|c|r|r|r|r|r|r|}
\hline \multirow{2}{*}{ Venue } & \multicolumn{3}{|c|}{ Vodka } & \multicolumn{3}{|c|}{ Lager } & \multicolumn{3}{c|}{ Alcopops } & \multicolumn{3}{c|}{ ANY } \\
\cline { 2 - 15 } & OG & SG & P & OG & SG & P & OG & SG & P & OG & SG & P \\
\hline Armageddon & 0 & 0 & 8 & 0 & 0 & 7 & 0 & 0 & 8 & $\mathbf{0}$ & $\mathbf{0}$ & $\mathbf{2 3}$ \\
\hline Xanadu & 0 & 0 & 7 & 0 & 0 & 7 & 0 & 0 & 8 & $\mathbf{0}$ & $\mathbf{0}$ & $\mathbf{2 2}$ \\
\hline Idols & 0 & 0 & 8 & 0 & 0 & 8 & 0 & 0 & 6 & $\mathbf{0}$ & $\mathbf{0}$ & $\mathbf{2 2}$ \\
\hline Rapture & 0 & 0 & 8 & 0 & 0 & 7 & 0 & 0 & 6 & $\mathbf{0}$ & $\mathbf{0}$ & $\mathbf{2 1}$ \\
\hline Chocolate & 0 & 0 & 8 & 0 & 0 & 8 & 0 & 0 & 4 & $\mathbf{0}$ & $\mathbf{0}$ & $\mathbf{2 0}$ \\
\hline Saturn* & 3 & 5 & 0 & 2 & 2 & 0 & - & - & - & $\mathbf{5}$ & $\mathbf{7}$ & $\mathbf{0}$ \\
\hline Sinatra's & 2 & 5 & 1 & 6 & 2 & 0 & 0 & 0 & 7 & $\mathbf{8}$ & $\mathbf{7}$ & $\mathbf{8}$ \\
\hline Tropicana & 2 & 6 & 0 & 2 & 6 & 0 & 0 & 1 & 2 & $\mathbf{4}$ & $\mathbf{1 3}$ & $\mathbf{2}$ \\
\hline TOTAL & $\mathbf{7}$ & $\mathbf{1 6}$ & $\mathbf{4 0}$ & $\mathbf{1 0}$ & $\mathbf{1 0}$ & $\mathbf{3 7}$ & $\mathbf{0}$ & $\mathbf{1}$ & $\mathbf{4 1}$ & $\mathbf{1 7}$ & $\mathbf{2 7}$ & $\mathbf{1 1 8}$ \\
\hline
\end{tabular}

* Note - 'Saturn' did not sell alcopops and by the second data sweep was serving lager in aluminium cans ( $n=4$ observations) which appeared to be being recycled, as these empties were left longer than other vessels and were later gathered up in a plastic bag. 